\title{
Maternal Smoking in Pregnancy: Do the Effects on Innate (Toll-Like Receptor) Function Have Implications for Subsequent Allergic Disease?
}

\author{
Susan L. Prescott, MBBS, BMedSci, PhD, FRACP and Paul S. Noakes, BSc(Hons), PhD
}

\begin{abstract}
Subtle increases in immaturity of immune function in early infancy have been implicated in the rising susceptibility to allergic disease, particularly relative impairment of type 1 interferon (IFN)- $\gamma$ responses in the neonatal period. Although genetic predisposition is a clear risk factor, the escalating rates of allergic disease in infancy suggest that environmental factors are also implicated. We previously showed that maternal smoking in pregnancy may impair neonatal IFN- $\gamma$ responses. Our more recent studies now indicate that this common avoidable toxic exposure is also associated with attenuation of innate immune function, with attenuated Toll-like receptor (TLR)-mediated microbial responses (including TLR-2, $-3,-4$, and -9 responses). Most notably, the effects were more marked if the mothers were also allergic. In this review, we discuss the significance of these observations in the context of the emerging hypothesis that variations in TLR function in early life may be implicated in allergic propensity. There is now growing evidence that many of the key pathways involved in subsequent T-cell programming and regulation (namely, antigen-presenting cells and regulatory $T$ cells) rely heavily on microbe-driven TLR activation for maturation and function. Factors that influence the function and activity of these innate pathways in early life may contribute to the increasing predisposition for allergic disease. Although "cleaner" environments have been implicated, here we explore the possibility that other common environmental exposures (such as maternal smoking) could also play a role.
\end{abstract}

Key words: allergic disease, cord blood, cotinine, cytokines, innate immunity, pregnancy, smoking, Toll-like receptors

A striking increase in immune-mediated diseases has been one of the most concerning changes in disease prevalence during the late twentieth century. Although the reasons for this are not clear, environmental changes are clearly implicated. This change has involved major increases in apparently diverse disease processes, including a spectrum of allergic diseases and autoimmune diseases. ${ }^{1}$ This increase in immune dysregulation, often very early in life, has led to intense interest in factors that influence to early immune maturation.

Susan L. Prescott and Paul S. Noakes: School of Paediatrics and Child Health, University of Western Australia, Princess Margaret Hospital for Children, Perth, Western Australia.

Prof. Prescott is funded by the National Health and Medical Council (of Australia).

Correspondence to: Associate Professor Susan L. Prescott, School of Paediatrics and Child Health, University of Western Australia, Princess Margaret Hospital for Children, GPO Box D184, Perth, Western Australia 6840.

DOI $10.2310 / 7480.2006 .00017$
Although microbial factors are known to enhance immune maturation, factors that may inhibit early immune maturation are less well documented. Here we explore the potential role of maternal smoking in pregnancy on infant immune development. Specifically, we examine the novel hypothesis that maternal smoking causes a relative impairment of innate defense through effects on the developing immune system in pregnancy. We speculate that these effects may not only contribute to the increased risk of infection ${ }^{2}$ but may also be implicated in the increased rates of other forms of chronic inflammatory respiratory disease seen in these children, ${ }^{3}$ including asthma and recurrent wheezing. ${ }^{4,5}$ Whereas there have been extensive studies of the effects of cigarette smoking on neonatal lung mechanics, ${ }^{6,7}$ there is only relatively limited information about the effects on developing immune responses.

The prevalence of smoking in women of child-bearing age generally ranges between 17 and 35\% around the world. Although the rates of smoking in pregnancy have generally declined over the last 10 years, a significant proportion (10-20\%) of women continue to smoke in 
pregnancy, and this is heavily influenced by maternal age, ethnicity, education, and socioeconomic level. ${ }^{8-11}$

At this stage, it is unclear if the decline in maternal smoking is linked to the declining rates of asthma in some developed countries during the same period. ${ }^{12}$ Although it is unlikely that maternal smoking is the primary causal factor in the changing prevalence of asthma, we are proposing that it is an important contributing factor, with significant potential to interact with other genetic factors and environmental risk factors to modify disease propensity.

\section{Preliminary Evidence that Maternal Smoking Has Immunologic Effects on the Developing Fetus}

There has been growing evidence that subtle increases in immaturity of immune function, particularly Th1 interferon (IFN) $-\gamma$ responses, during early infancy may be associated with allergy risk and subsequent disease. ${ }^{13-16}$ We previously noted that maternal smoking in pregnancy is associated with lower Th1 responses to polyclonal stimulation, ${ }^{17}$ although this study measured messenger ribonucleic acid (mRNA) expression rather than protein levels. Others have also noted differences in the immune function of neonates whose mothers smoked in pregnancy. Early studies noted that parental smoking is associated with higher cord blood immunoglobulin E (IgE) levels, ${ }^{18}$ and, subsequently, Devereux and colleagues observed that maternal smoking is associated with stronger neonatal allergen-specific responses, ${ }^{19}$ providing preliminary evidence that maternal smoking has effects on fetal cellular immune function. In our more recent studies, we measured the specific effects of smoking on Toll-like receptor (TLR) innate defence pathways (below), which could both explain an increased susceptibility to infection and have implications for subsequent allergen-specific immune development.

\section{Role of Innate Immunity in Subsequent Immune Development}

Innate immunity plays a key role in immune defence in the neonatal period before the development of environmentally driven adaptive immune responses. This aspect of the immune system is activated through highly conserved receptors, including the TLR family, that recognize a broad range of microbial agents. ${ }^{20}$ These receptors are found on many cells involved in immediate host defence, such as neutrophils, natural killer cells, and antigen-presenting cells (APCs). Differential expression of TLR on these cell types (as summarized in Figure 1) allows specialized responses to different microbial components. Activation of APCs through the TLR also has implications for adaptive immune function as these cells play a critical role in programming effector responses. Once activated via these pathways, dendritic cells (DCs) and other APCs show

\begin{tabular}{|c|c|c|}
\hline TLR family & Ligands (origin) & Cell types \\
\hline TLR 1/2/6 & $\begin{array}{l}\text { Pansorbin, Pam }{ }_{3} \text { Cys } \\
\text { (chemicals) } \\
\text { PGN, LTA (Gram-positive } \\
\text { bacteria } \\
\text { Porins (Neisseria), Zymosan } \\
\text { (fungi) }\end{array}$ & $\begin{array}{l}\text { Granulocytes, macrophages, } \\
\text { mDCs, monocytes }\end{array}$ \\
\hline TLR3 & $\begin{array}{l}\text { Poly (l:C) (chemicals) } \\
\text { Double stranded RNA } \\
\text { [dsRNA] (v irus) }\end{array}$ & $\begin{array}{l}\text { NK cells } \\
\text { DCs, macrophage }\end{array}$ \\
\hline TLR4 & $\begin{array}{l}\text { LPS (Gram-negative } \\
\text { bacteria } \\
\text { Taxol (plant), HSP60, } \\
\text { HSP70 (host) }\end{array}$ & $\begin{array}{l}\text { B cells, DCs, macrophages } \\
\text { monocytes, granulocytes, } \\
\text { Regulatory T cells }\end{array}$ \\
\hline TLR5 & Bacterial flagellin & Regulatory T cells, Epithelial cells \\
\hline TLR7/8 & $\begin{array}{l}\text { ssRNA (ant - viral } \\
\text { compounds) }\end{array}$ & DCs, regulatory $\mathrm{T}$ cells \\
\hline TLR9 & CpG-ODN (bacteria) & B cells, pDCs, Macrophages, \\
\hline TLR10 & ? & $\mathrm{B}$ cells, pDCs, \\
\hline TLR 11 & $\begin{array}{l}\text { Ligand on uropathogenic } \\
\text { bacteria }\end{array}$ & ? \\
\hline
\end{tabular}

Figure 1. Cell surface expression of Toll-like receptors and their ligands. 
enhanced expression of costimulatory molecules and cytokines (including interleukin [IL]-12), which favour Th1 immune differentiation. TLRs (TLR-4, -5, -7, and -8) have also more recently been identified on $\mathrm{CD} 4^{+} \mathrm{CD} 25^{+} \mathrm{T}$ regulatory cells ${ }^{21}$ that play a critical role in controlling immune responses. ${ }^{22}$ Thus, it has been proposed that TLRmediated activation of both APCs and regulatory $\mathrm{T}$ cells may play an important role in reducing the risk of Th2mediated allergic responses. ${ }^{22,23}$ This is obviously of most relevance in early life when programming of immunologic function is initiated.

We speculate that TLR function matures in the postnatal period and that children who develop allergic disease have differences in these development patterns as a result of genetic predisposition and/or environmental influences. This hypothesis is based on preliminary evidence that TLR function is developmentally regulated, with differences between infants and adults, ${ }^{24,25}$ and that genetic and environmental factors can modify TLR function in early life, as discussed below.

\section{Emerging Interest in the Role of Early TLR Function in the Risk of Allergic Disease}

At this stage, there is only preliminary evidence that children at high risk of allergic disease have altered TLR function. First, in a small study, newborns of allergic women $(N=9)$ had significantly lower in vitro responses after TLR-2 ligation (with peptidoglycan) compared with those of nonallergic women $(p=.03){ }^{26}$ In another larger study $(N=185)$, maternal allergy was associated with significantly lower levels of TLR-2, TLR-4, and CD14 mRNA in cord blood samples. ${ }^{27}$ Neonates at "high risk" of allergy have also been noted to have altered generation of putative $\mathrm{T}$ regulatory cell populations after lipopolysaccharide (LPS) stimulation, presumably through TLR-4 pathways. ${ }^{28}$ At this stage, the significance of these findings is unclear. Maternal allergy appears to confer "allergy risk" not only by genetic inheritance but also by direct immune interactions in pregnancy, as we recently reported. ${ }^{29}$

\section{Evidence that Environmental Factors that Modify Early TLR-Mediated Immune Activation Can Alter Allergy Risk}

There is good evidence in animal models that TLR activation using microbial products can modify immune development and the risk of allergic sensitization, although this has not been examined directly in humans. Blumer and colleaguers recently demonstrated that TLR-4 activation (giving endotoxin) in pregnancy enhanced neonatal Th1 IFN- $\gamma$ responses and inhibited (ovalbumin) allergen sensitization in the offspring. ${ }^{30}$ Tulic and colleagues showed similar effects of the same TLR-4 ligand in the postnatal period, but, notably, the inhibition of allergic responses was seen only when endotoxin was given before responses were established. ${ }^{31}$ In humans, exposure to farming animals (and presumably higher endotoxin levels) has been associated with both increased gene expression (of TLR-2: odds ratio 1.16, 95\% confidence interval [CI] 1.07-1.26; of TLR-4: odds ratio 1.12, 95\% CI 1.04-1.2) and the risk of allergic sensitization (adjusted odds ratio 0.58, 95\% CI 0.39-0.86). ${ }^{32}$ Intervention studies also suggest that administration of bacterial products to children may have clinical $^{33,34}$ and immune ${ }^{35}$ effects. Although it has been inferred that these variations in microbial exposure may be responsible for differences in innate (and subsequent cognate) immune function, this has not been documented directly.

There is also evidence that genetically conferred variations in TLR function may be implicated in allergic disease. TLR-2 genetic polymorphisms were shown to have a protective effect on asthma. ${ }^{36}$ Notably, the "protective" effect was seen only when children were raised in environments with "high" microbial burden, illustrating the interactive effects of genetic and environmental factors on these pathways. Polymorphisms in the TLR4 gene have been associated with atopic asthma in some $e^{37}$ but not all studies, ${ }^{38,39}$ raising questions over the functional significance of these polymorphisms. These conflicting results could also suggest complex gene and environment interactions and that the same genetic background might result in the expression of different phenotypes in different environments. This requires large-scale population studies involving many thousands of children, which are becoming more realistic as multicentre collaborations develop further in this field.

Together, these findings suggest that alterations in TLR function, either as a result of differences in early environmental exposures or functional genetic polymorphisms, have an effect on subsequent development of adaptive immune function. Here we explore the effects of maternal smoking on TLR function and these interactions.

\section{Effects of Maternal Smoking in Innate (TLR) Immune Development}

The increased rate of respiratory disease ${ }^{40}$ and infection ${ }^{2}$ in infants of smoking mothers is well recognized. These 
effects may be mediated by a number of pathways, including in utero effects and ongoing toxic effects in the postnatal period. Adverse effects on airway development are well documented, ${ }^{41-45}$ and there is also preliminary evidence that maternal smoking may also have effects on immune development. ${ }^{17,19}$ We now speculate that the toxic effects of maternal smoking may be having effects on the development and function of innate responses, and this may be implicated in the susceptibility to both infection and asthma in exposed infants.

We recently addressed this hypothesis in a prospective cohort study that compared innate immune function in the neonates of women who smoked in pregnancy $(n=58)$ with that of the neonates of nonsmokers $(n=59)$. Women were recruited early in pregnancy when detailed clinical and smoking histories were collected. Cotinine levels were measured in maternal and cord blood plasma to confirm differences in cigarette smoke exposure. This demonstrated significantly higher levels in the smoking group $(p<.001)$, with largely undetectable levels in the nonsmokers, and significant correlations between cotinine levels and selfreported smoke exposure. Cord blood mononuclear cells were isolated to assess the effects of maternal smoking in pregnancy on TLR function, using optimal doses of specific microbial ligands for TLR-2 ligand (pansorbin [Staphylococcus aureus] 0.1\%), TLR-3 ligand (polyinosinicpolycytidylic acid:cytosine-phosphate-guanine [CpG] $30 \mu \mathrm{g} /$ $\mathrm{mL}$ ), TLR-4 ligand (LPS $10 \mathrm{ng} / \mathrm{mL}$ ), and TLR-9 ligand (CpG $1.66 \mu \mathrm{g} / \mathrm{mL}$ ). Functional responses to these ligands were assessed by cytokine production (tumor necrosis factor $[\mathrm{TNF}]-\alpha$, IL-10, and IL-6, principally derived from APCs in this culture system) after 48 hours, as previously described. ${ }^{46}$ We observed that the infants of smoking mothers showed significant attenuation of a number of aspects of innate TLRmediated responses compared with the infants of nonsmokers. ${ }^{47}$ This included significantly lower cytokine responses following TLR-2 (TNF- $\alpha, p=.004$; IL-6, $p=$ .045 ; IL-10, $p=.014$ ), TLR-3 (TNF- $\alpha, p=.044)$, TLR-4 (TNF- $\alpha, p=.034$ ), and TLR-9 (IL-6, $p=.046$ ) activation. There were also consistent negative correlations between cotinine levels and cytokine (IL-6, IL-10, and TNF- $\alpha$ ) responses to these TLRs. Although women who smoked were also more likely to have lower educational levels and consume other recreational drugs during pregnancy, the relationships between maternal smoking status and immune function remained evident after these effects were accounted for in multiple regression modeling. These observations appear to confirm our hypothesis that maternal smoking may attenuate aspects of innate immune function in the neonatal period; however, it remains possible that other maternal factors that could not be measured could contribute the differences between these populations.

\section{Possible Pathways of Influence: Immune Effects of Oxidative Stress?}

Cigarette smoke is a major source of free radicals and oxidative stress. ${ }^{48}$ Recent studies have identified smokinginduced disruption of oxygen-related responses that are known to play a key role in placental cytotrophoblast proliferation and differentiation during critical early stages of development. ${ }^{49}$ Most notably, effects were also seen when women were passively exposed to tobacco smoke. ${ }^{49}$ Foreseeably, these disruptions in antioxidant systems could lead to further disruptions of local immune function in the placenta and in the fetus. Oxidative stress plays a major role in inflammation. Macrophages infiltrate inflamed tissue and release reactive oxygen species and reactive nitrogen species and, in doing so, become depleted of antioxidants, as reflected by their reduced glutathione status. ${ }^{50}$ It has been demonstrated that a change in the "redox" status (reduced glutathione) of APCs (macrophages) promotes CD4 T-cell Th2 differentiation ${ }^{50}$ and the production of IL-4 and IL-5, which contribute allergic inflammation. Specifically, oxidative stress promotes proTh2 signaling by APCs by reducing IL-12 production in mice ${ }^{50}$ and humans (which can be reversed by antioxidants ${ }^{51}$ ). Thus, the effects of modifying oxidative function provide a plausible pathway for smoking in modifying developing immune responses.

\section{Molecular Targets: Effects on Transcription Factors?}

The production of inflammatory cytokines is mediated through transcription factors such as nuclear factor (NF)$\kappa \mathrm{B}$ and activator protein $1 .{ }^{52,53}$ In vitro studies demonstrate that cigarette smoke extracts reduce proinflammatory LPS-induced TLR-4 signaling by inhibiting transcription factors. ${ }^{54,55}$ More recently, Valacchi and colleagues demonstrated that a major constituent of cigarette smoke (acrolein) suppresses epithelial production of inflammatory chemokine IL-8 through direct inhibition of NF- $\kappa B .{ }^{56}$ Based on these findings, we speculate that smoking may affect TLR signaling via nuclear effects on transcription factors (Figure 2). There may be preliminary evidence that this occurs following direct mucosal exposure, ${ }^{54,56}$ and it is possible that the systemic in utero effects observed in our study could be mediated through a similar pathway. This could be assessed in future studies 


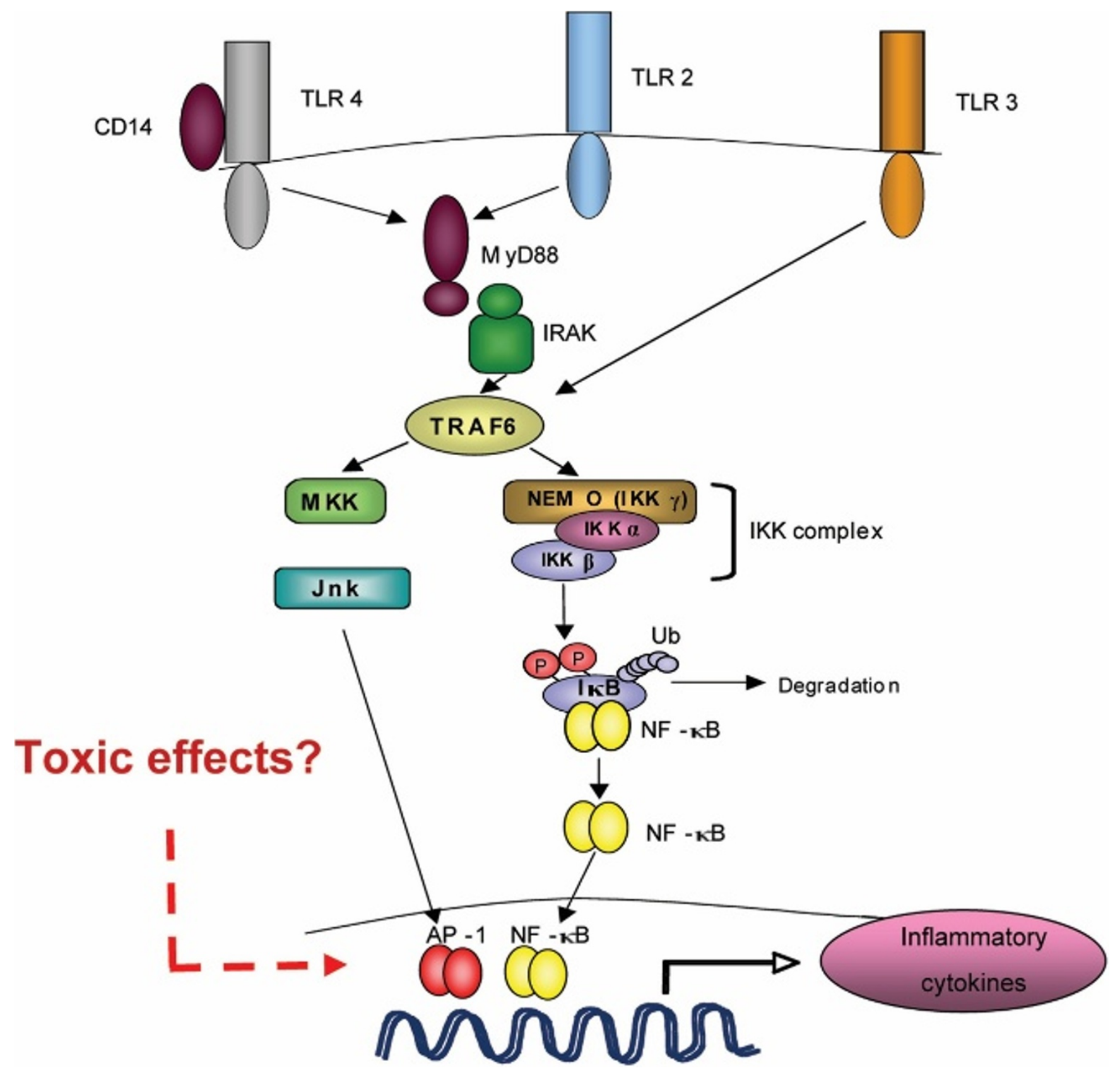

Figure 2. Potential mechanisms of action: possible effects of smoking in common transduction pathways. Reproduced with permission from Hole J. The innate immune mechanisms of prostate epithelium during bacterial infection [thesis]. Perth: Department of Microbiology, University of Western Australia; 2003.

examining the effects of maternal smoking on neonatal mRNA expression following TLR ligation.

\section{Differential Effects of Maternal Smoking in Infants at High Risk of Allergy?}

Our study (above) included approximately an equal number of allergic $(n=62)$ and nonallergic women $(n$
$=60$ ), who were distributed equally among the smoking group ( $n=32$ allergic) and the nonsmokers $(n=30$ allergic). Allergic status was confirmed by allergen skinprick testing (SPT) to common allergens (with at least one positive SPT to dust mite, cats, dogs, grass pollens, moulds, or cockroaches).

First, we examined the effects of maternal allergy on TLR-mediated responses (as the proportion of smokers in 
these groups was the same). Although other studies (discussed above) have noted that infants at high risk of allergic disease (based on maternal allergy) have reduced TLR expression ${ }^{27}$ and function, ${ }^{26}$ we did not see any consistent effects in this study. The only difference that approached statistical significance was a trend for lower IL-10 responses following TLR-2 ligation (with pansorbin) $(p=.06)$ in the allergic group $(n=62)$.

Second, we determined if infants at high risk of allergy (maternal allergy) are also more susceptible to the effects of maternal smoking. Whereas TNF- $\alpha$ responses (to TLR$2,-3$, and -4 activation) were significantly attenuated in smokers, this was seen only in infants of atopic mothers (for TLR-2, $p=.014$; TLR-3, $p=.048$; and TLR-4, $p=$ .014 ), with no significant effects of smoking in the nonatopic group. Although there was a trend in the nonatopic group for smokers to have impaired TNF- $\alpha$ responses to TLR-2, this did not reach statistical significance $(p=.094)$. These findings indicate that the effects of smoking on TNF- $\alpha$ responses are significantly enhanced by maternal allergy. Thus, both maternal allergy $^{27}$ and function ${ }^{26}$ and maternal smoking ${ }^{47}$ may have effects on aspects of neonatal immune function (although in our study, smoking had a more significant effects). Although some of these effects are independent, our data also suggest some interactive potentiating effects. Specifically, we have shown that maternal atopic status selectively amplifies the effect of smoking on some activation pathways.

\section{Implications of Our Findings for the Risk of Subsequent Development of Allergic Disease?}

Whereas maternal smoking in pregnancy has been associated with an increased risk of asthma and reduced lung function is well described, ${ }^{4,5}$ the relationship between subsequent atopic risk has been more controversial. A number of studies have linked parental smoking with markers of atopy in children, ${ }^{57,58}$ including serum IgE levels, ${ }^{7,59-62}$ eosinophilia, ${ }^{7,63}$ and positive SPTs. ${ }^{64}$ Despite this, a systematic review by Strachan and Cook in 1998 did not find any conclusive association. ${ }^{65}$ However, this did not include the results of a more recent study by Kulig and colleagues, which reported a significantly higher risk of sensitization to food allergens (odds ratio $2.3,95 \%$ CI 1.14.6) in children exposed to maternal smoking compared with unexposed children. ${ }^{66}$ It is now well recognized that genetic polymorphisms in antioxidant pathways may contribute to differences in susceptibility to the effects of cigarette smoke, ${ }^{67}$ and genetic differences could account for some of the differences between studies.

Our recent findings could provide an important pathway through which maternal smoking could potentiate the development of allergy. We have shown that smoking has direct effects on neonatal APC function, as detected by impaired innate responses to microbial stimulation. It could be argued that persistent immaturity of APC responses to bacteria could interfere with microbedriven Th1 maturation (which is mediated via TLR pathways). Other studies have shown an in vitro immunosuppressive effect of nicotine on APC (DC) function, including as antigen-capturing, cytokine production (particularly IL-12 production), and eventually T-cell priming and polarization. ${ }^{68}$ This has implications for allergic risk as impaired Th1 function in the perinatal period has been linked to allergic risk in many studies. ${ }^{13-16}$ TLR activation is also important for activation of $\mathrm{T}$ regulatory cells, which are also important for suppression of allergic Th2 responses. Together, these effects could contribute to increased allergic risk.

However, at this stage, it is not clear how long these effects on APC function might persist in the postnatal period. It could also be argued that a resultant increased susceptibility to infection could provide a strong source of APC-driven Th1 immune maturation. Thus, although it is possible that the effects of maternal smoking on early TLR function may contribute to the well-documented increase in early postnatal susceptibility to respiratory tract infections in exposure infants, ${ }^{2}$ further studies are needed to examine the longitudinal effects on the development of allergen-specific memory.

\section{Concluding Comments}

In summary, our findings show that in addition to the effects on developing airways, maternal smoking in pregnancy also has significant immunologic effects that could contribute to increased risk of respiratory infections and asthma. These effects appear to be mediated through effects on TLR-mediated innate response pathways, which also promote regulatory pathways in the inhibition of allergic immune responses. This highlights the fact that other environmental interactions are highly relevant to the "hygiene hypothesis." Specifically, although the level of early microbial exposure is the strongest determinant of TLR-mediated immune maturation, our findings demonstrate that other environmental exposures (such as maternal smoking) may also have an influence. There is no doubt that smoking should be avoided in all 
pregnancies because of the many adverse effects, and our studies suggest that the adverse effects on fetal immune development could be even greater in atopic women.

\section{Acknowledgements}

We wish to acknowledge the staff and patients who assisted in our studies. We are particularly grateful to the obstetricians and midwives at King Edward Memorial Hospital and St John of God Hospital, Subiaco, Western Australia. Finally, we wish to acknowledge Ms. Elaine Pascoe for statistical advice.

\section{References}

1. Bach JF. The effect of infections on susceptibility to autoimmune and allergic diseases. N Engl J Med 2002;347:911-20.

2. Jedrychowski W, Flak E. Maternal smoking during pregnancy and postnatal exposure to environmental tobacco smoke as predisposition factors to acute respiratory infections. Environ Health Perspect 1997;105:302-6.

3. Chan-Yeung M, Dimich-Ward H. Respiratory health effects of exposure to environmental tobacco smoke. Respirology 2003;8: 131-9.

4. Gilliland FD, Berhane K, Li YF, et al. Effects of early onset asthma and in utero exposure to maternal smoking on childhood lung function. Am J Respir Crit Care Med 2003;167:917-24.

5. Gilliland FD, Berhane K, McConnell R, et al. Maternal smoking during pregnancy, environmental tobacco smoke exposure and childhood lung function. Thorax 2000;55:271-6.

6. Le Souef PN. Pediatric origins of adult lung diseases. 4. Tobacco related lung diseases begin in childhood. Thorax 2000;55: 1063.

7. Ronchetti R, Macri F, Ciofetta G, et al. Increased serum IgE and increased prevalence of eosinophilia in 9-year-old children of smoking parents. J Allergy Clin Immunol 1990;86(3 Pt 1):4007.

8. Ananth CV, Kirby RS, Kinzler WL. Divergent trends in maternal cigarette smoking during pregnancy: United States 1990-99. Paediatr Perinat Epidemiol 2005;19:19-26.

9. Colman GJ, Joyce T. Trends in smoking before, during, and after pregnancy in ten states. Am J Prev Med 2003;24:29-35.

10. Mohsin M, Bauman AE. Socio-demographic factors associated with smoking and smoking cessation among 426,344 pregnant women in New South Wales, Australia. BMC Public Health 2005;5: 138.

11. Shaw M, Lawlor DA, Najman JM. Teenage children of teenage mothers: psychological, behavioural and health outcomes from an Australian prospective longitudinal study. Soc Sci Med 2006;62: 2526-39.

12. Robertson CF, Roberts MF, Kappers JH. Asthma prevalence in Melbourne schoolchildren: have we reached the peak? Med J Aust 2004;180:273-6.

13. Kondo N, Kobayashi Y, Shinoda S, et al. Reduced interferon gamma production by antigen-stimulated cord blood mono- nuclear cells is a risk factor of allergic disorders-6-year follow- up study. Clin Exp Allergy 1998;28:1340-4.

14. Tang MLK, Kemp AS, Thorburn J, Hill D. Reduced interferon gamma secretion in neonates and subsequent atopy. Lancet 1994; 344:983-5.

15. Rinas $\mathrm{U}$, Horneff $\mathrm{G}$, Wahn V. Interferon gamma production by cord blood mononuclear cells is reduced in newborns with a family history of atopic disease and is independent from cord blood IgE levels. Pediatr Allergy Immunol 1993;4:60-4.

16. Prescott SL, Macaubas C, Smallacombe T, et al. Reciprocal agerelated patterns of allergen-specific T-cell immunity in normal vs. atopic infants. Clin Exp Allergy 1998;28 Suppl 5:39-44; discussion $50-1$.

17. Noakes PS, Holt PG, Prescott SL. Maternal smoking in pregnancy alters neonatal cytokine responses. Allergy 2003;58:1053-8.

18. Magnusson C. Maternal smoking influences cord serum IgE and $\mathrm{IgD}$ levels and increases the risk for subsequent infant allergy. J Allergy Clin Immunol 1986;78:898-904.

19. Devereux G, Barker RN, Seaton A. Antenatal determinants of neonatal immune responses to allergens. Clin Exp Allergy 2002;32: $43-50$.

20. Aderem A, Ulevitch RJ. Toll-like receptors in the induction of the innate immune response. Nature 2000;406:782-7.

21. Caramalho I, Lopes-Carvalho T, Ostler D, et al. Regulatory T cells selectively express toll-like receptors and are activated by lipopolysaccharide. J Exp Med 2003;197:403-11.

22. Wills-Karp M, Santeliz J, Karp CL. The germless theory of allergic disease: revisiting the hygiene hypothesis. Nat Rev Immunol 2001; 1:69-75.

23. Holt P, Macaubas C, Prescott S, Sly P. Microbial stimulation as an aetiologic factor in atopic disease. Allergy 1999;54 Suppl 49:126.

24. Levy O, Zarember KA, Roy RM, et al. Selective impairment of TLR-mediated innate immunity in human newborns: neonatal blood plasma reduces monocyte TNF-alpha induction by bacterial lipopeptides, lipopolysaccharide, and imiquimod, but preserves the response to R-848. J Immunol 2004;173:4627-34.

25. De Wit D, Tonon S, Olislagers V, et al. Impaired responses to tolllike receptor 4 and toll-like receptor 3 ligands in human cord blood. J Autoimmun 2003;21:277-81.

26. Amoudruz P, Holmlund U, Malmstrom V, et al. Neonatal immune responses to microbial stimuli: is there an influence of maternal allergy? J Allergy Clin Immunol 2005;115:1304-10.

27. Krauss-Etschmann S, Hartl D, Heinrich J, et al. Association between levels of Toll-like receptors 2 and 4 and CD14 mRNA and allergy in pregnant women and their offspring. Clin Immunol 2006;118:292-9.

28. Haddeland U, Karstensen AB, Farkas L, et al. Putative regulatory T cells are impaired in cord blood from neonates with hereditary allergy risk. Pediatr Allergy Immunol 2005;16:104-12.

29. Prescott SL, Taylor A, Roper J, et al. Maternal reactivity to fetal alloantigens is related to newborn immune responses and subsequent allergic disease. Clin Exp Allergy 2005;35:41725.

30. Blumer N, Herz U, Wegmann M, Renz H. Prenatal lipopolysaccharide-exposure prevents allergic sensitisation and airway inflammation, but not airway responsiveness in a murine model of experimental asthma. Clin Exp Allergy 2005;35:397-402. 
31. Tulic MK, Wale JL, Holt PG, Sly PD. Modification of the inflammatory response to allergen challenge after exposure to bacterial lipopolysaccharide. Am J Respir Cell Mol Biol 2000;22: 604-12.

32. Ege MJ, Bieli C, Frei R, et al. Prenatal farm exposure is related to the expression of receptors of the innate immunity and to atopic sensitization in school-age children. J Allergy Clin Immunol 2006; 117:817-23.

33. Arkwright PD, David TJ. Intradermal administration of a killed Mycobacterium vaccae suspension (SRL 172) is associated with improvement in atopic dermatitis in children with moderate-tosevere disease. J Allergy Clin Immunol 2001;107:531-4.

34. Weston S, Halbert A, Richmond P, Prescott SL. Effects of probiotics on atopic dermatitis: a randomised controlled trial. Arch Dis Child 2005;90:892-7.

35. Prescott SL, Dunstan JA, Hale J, et al. Clinical effects of probiotics are associated with increased interferon-gamma responses in very young children with atopic dermatitis. Clin Exp Allergy 2005;35: 1557-64.

36. Eder W, Klimecki W, Yu L, et al. Toll-like receptor 2 as a major gene for asthma in children of European farmers. J Allergy Clin Immunol 2004;113:482-8.

37. Fageras Bottcher M, Hmani-Aifa M, Lindstrom A, et al. A TLR4 polymorphism is associated with asthma and reduced lipopolysaccharide-induced interleukin-12(p70) responses in Swedish children. J Allergy Clin Immunol 2004;114:561-7.

38. Yang IA, Barton SJ, Rorke S, et al. Toll-like receptor 4 polymorphism and severity of atopy in asthmatics. Genes Immun 2004;5:41-5.

39. Noguchi E, Nishimura F, Fukai $\mathrm{H}$, et al. An association study of asthma and total serum immunoglobin E levels for Toll-like receptor polymorphisms in a Japanese population. Clin Exp Allergy 2004;34:177-83.

40. DiFranza JR, Aligne CA, Weitzman M. Prenatal and postnatal environmental tobacco smoke exposure and children's health. Pediatrics 2004;113(4 Suppl):1007-15.

41. Brown RW, Hanrahan JP, Castille RG, Tager IB. Effect of maternal smoking during pregnancy on passive respiratory mechanics in early infancy. Pediatr Pulmonol 1995;19:23-8.

42. Hanrahan JP, Tager IB, Segal MR, et al. The effect of maternal smoking during pregnancy on early infant lung function. Am Rev Respir Dis 1992;145:1129-35.

43. Hoo A, Matthias H, Dezateux C, et al. Respiratory function among preterm infants whose mothers smoked during pregnancy. Am J Respir Crit Care Med 1998;158:700-5.

44. Lodrup Carlsen KC, Jaakkola JJ, Nafstad P, Carlsen KH. In utero exposure to cigarette smoking influences lung function at birth. Eur Respir J 1997;10:1774-9.

45. Stick SM, Burton PR, Gurrin L, et al. Effects of maternal smoking during pregnancy and a family history of asthma on respiratory function in newborn infants. Lancet 1996;348:1060-4.

46. Dunstan J, Mori TA, Barden A, et al. Fish oil supplementation in pregnancy modifies neonatal allergen-specific immune responses and clinical outcomes in infants at high risk of atopy: a randomised controlled trial. J Allergy Clin Immunol 2003;112: 1178-84.

47. Noakes P, Hale J, Thomas R, et al. Maternal smoking is associated with impaired neonatal Toll-like receptor (TLR) mediated immune responses. Eur Respir J 2006;28:721-9.
48. Bluhm AL, Weistein J, Souza JA. Free radicals in tobacco smoke. Nature 1971;229:500.

49. Genbacev O, McMaster MT, Zdravkovic T, Fisher SJ. Disruption of oxygen-regulated responses underlies pathological changes in the placentas of women who smoke or who are passively exposed to smoke during pregnancy. Reprod Toxicol 2003;17:50918.

50. Murata Y, Shimamura T, Hamuro J. The polarization of $\mathrm{T}(\mathrm{h}) \mathrm{l} /$ $\mathrm{T}(\mathrm{h}) 2$ balance is dependent on the intracellular thiol redox status of macrophages due to the distinctive cytokine production. Int Immunol 2002;14:201-12.

51. Utsugi M, Dobashi K, Ishizuka T, et al. c-Jun N-terminal kinase negatively regulates lipopolysaccharide-induced IL-12 production in human macrophages: role of mitogen-activated protein kinase in glutathione redox regulation of IL-12 production. J Immunol 2003;171:628-35.

52. Zhou L, Tan A, Iasvovskaia $S$, et al. Ras and mitogen-activated protein kinase kinase kinase-1 coregulate activator protein-1- and nuclear factor-kappaB-mediated gene expression in airway epithelial cells. Am J Respir Cell Mol Biol 2003;28:762-9.

53. Nareika A, He L, Game BA, et al. Sodium lactate increases LPSstimulated MMP and cytokine expression in U937 histiocytes by enhancing AP-1 and NF-kappaB transcriptional activities. Am J Physiol Endocrinol Metab 2005;289:E534-42.

54. Laan M, Bozinovski S, Anderson GP. Cigarette smoke inhibits lipopolysaccharide-induced production of inflammatory cytokines by suppressing the activation of activator protein-1 in bronchial epithelial cells. J Immunol 2004;173:4164-70.

55. Kim E, Kang BY, Kim TS. Inhibition of interleukin-12 production in mouse macrophages by hydroquinone, a reactive metabolite of benzene, via suppression of nuclear factor-kappaB binding activity. Immunol Lett 2005;99:24-9.

56. Valacchi G, Pagnin E, Phung A, et al. Inhibition of NFkappaB activation and IL-8 expression in human bronchial epithelial cells by acrolein. Antioxidants Redox Signaling 2005;7:25-31.

57. Martinez FD, Antognoni G, Macri F, et al. Parental smoking enhances bronchial responsiveness in nine-year-old children. Am Rev Respir Dis 1988;138:518-23.

58. Weiss ST, Tager IB, Munoz A, Speizer FE. The relationship of respiratory infections in early childhood to the occurrence of increased levels of bronchial responsiveness and atopy. Am Rev Respir Dis 1985;131:573-8.

59. el-Nawawy A, Soliman AT, el-Azzouni O, et al. Effect of passive smoking on frequency of respiratory illnesses and serum immunoglobulin-E (IgE) and interleukin-4 (IL-4) concentrations in exposed children. J Trop Pediatr 1996;42:166-9.

60. Kulig M, Bergmann R, Klettke $U$, et al. Natural course of sensitization to food and inhalant allergens during the first 6 years of life. J Allergy Clin Immunol 1999;103:1173-9.

61. Wjst M, Heinrich J, Liu P, et al. Indoor factors and IgE levels in children. Allergy 1994;49:766-71.

62. Soyseth V, Kongerud J, Boe J. Postnatal maternal smoking increases the prevalence of asthma but not of bronchial hyperresponsiveness or atopy in their children. Chest 1995;107: 389-94.

63. Halonen M, Stern D, Lyle S, et al. Relationship of total serum IgE levels in cord and 9-month sera of infants. Clin Exp Allergy 1991; 21:235. 
64. Lindfors $\mathrm{A}$, van Hage-Hamsten $\mathrm{M}$, Rietz $\mathrm{H}$, et al. Influence of interaction of environmental risk factors and sensitization in young asthmatic children. J Allergy Clin Immunol 1999;104:755.

65. Strachan DP, Cook DG. Health effects of passive smoking. 5. Parental smoking and allergic sensitisation in children. Thorax 1998;53:117-23.

66. Kulig M, Luck W, Lau S, et al. Effect of pre- and postnatal tobacco smoke exposure on specific sensitization to food and inhalant allergens during the first 3 years of life. Multicenter Allergy Study Group, Germany. Allergy 1999;54:220-8.

67. Kabesch M, Hoefler C, Carr D, et al. Glutathione S transferase deficiency and passive smoking increase childhood asthma. Thorax 2004;59:569-73.

68. Nouri-Shirazi M, Guinet E. Evidence for the immunosuppressive role of nicotine on human dendritic cell functions. Immunology 2003;109:365-73. 